\title{
Penerapan Metode Sobel Edge Detection dan Image Processing Untuk Mengetahui Diameter Apel Fuji Menggunakan Aplikasi Matlab
}

\author{
Alima Hakkon Hasibuan*, Taronisokhi Zebua, Rivalri Kristianto Hondro \\ Program Studi Teknik Informatika, Universitas Budi Darma, Medan, Indonesia \\ Email: 1," alimahsb95@gmail.com, ${ }^{2}$ taronisokhi@stmik-budidarma.ac.id, ${ }^{3}$ rivalri@stmik-budidarma.ac.id \\ Email Penulis Korespondensi alimahsb95@gmail.com \\ Submitted 05-06-2020; Accepted 13-06-2020; Published 14-06-2020
}

\begin{abstract}
Abstrak
Apel fuji (Malus Domestika) merupakan buah yang banyak mengandung anti oksidan. Selain daging buah nya kulti apel juga mengandung pektin. Apel fuji berwarna merah dan sedikit garis kuning. Ukuran apel dapat mempengaruhi harga jual apel, penentuan ukuran apel dapat dilihat dari ukuran diameternya, mengukur diameter buah apel biasanya dilakukan secara visual dengan membandingkan apel. Berdasarkan masalah tersebut dibutuhkan suatu penelitian untuk mengembangkan sistem dalam menentukan ukuran diameter apel fuji dengan mengggunakan teknik pengolahan citra dengan mencari diameter. Proses pengukuran ini menggunakan aplikasi matlab dan menguji dengan metode deteksi tepi sobel dan image processing untuk melihat tepi yang lebih terlihat nyata garisnya. Hasil penelitian menunjukkan bahwa sistem yang dikembangkan mampu memperoleh gambar dan mengidentitikasi ukuran diameter apel fuji.
\end{abstract}

Kata Kunci: Apel fuji, Pengolahan Citra, Sobel, Diameter, Edge Detection.

\begin{abstract}
Fuji apples (Malus Domestika) are fruits that contain a lot of antioxidants. Besides the fruit flesh, the apple also contains pectin. Fuji apples are red and have a yellow line. The size of apples can affect the selling price of apples, the determination of the size of apples can be seen from the size of the diameter, measuring the diameter of apples is usually done visually by comparing apples. Based on these problems, a research is needed to develop a system to determine the diameter of fuji apples by using image processing techniques to find the diameter. This measurement process uses the matlab application and tests with the sobel edge detection method and image processing to see the more visible edges of the lines. The results showed that the developed system was able to obtain images and identify the diameter of fuji apples.
\end{abstract}

Keywords: Fuji Apple, Image Processing, Sobel, Diameter, Edge Detection.

\section{PENDAHULUAN}

Pada masa sekarang mengukur diameter buah apel masih banyak yang megukurnya dengan membandingkan ukuran apel, yaitu cara yang kurang tepat[1]. Mengetehui diameter sebuah apel dapat mengelompokkan apel yang berukuran besar dan kecil karna harga apel yang besar berbeda dengan harga apel yang kecil, adanya kendala tersebut maka dikembangkanlah sebuah aplikasi untuk mengetahui diameter menggunakan sebuah perancangan dengan terlebih dahulu mendeteksi tepi metode edge detection. Sehingga proses pengukuran diameter akurat. Citra adalah suatu representasi (gambaran), kemiripan, atau imitasi dari suatu objek. Citra digital merupakan gabungan titik, garis, bidang dan warna untuk menciptakan kemiripan suatu objek dengan objek aslinya. Citra bersifat analog dan digital. Citra digital dapat diolah komputer sedangkan citra analog tidak bisa diolah komputer, citra analog harus dikonversi ke digital agar bisa diproses oleh komputer. Pengolahan citra digital adalah hal-hal yang berkaitan dengan gambar, warna, transformasi dan lain sebagainya yang diproses menggunakan komputer [1].

Pengolahan citra dapat digunakan untuk memperbaiki kualitas warna citra, mengurang yangi noise, mendeteksi objek dan lain-lain. Adapun bidang-bidang yang telah menggunakan sistem komputer yang diaplikasikan adalah bidang industri, kedokteran, pertanian, hukum, biologi, keamanan dan lain sebagainya. Metode sobel terbentuk dari matriks 3x3 dan merupakan hasil dari konvolusi dengan Gx dan Gy. Dan metode ini memiliki kemampuan mengurangi noise sebelum tahap perhitungan deteksi tepi [2]. Dan metode sobel dapat digunakan untuk mendeteksi tepi dengan tingkat persentasi kesalahan yang kecil.

\section{METODE PENELITIAN}

\subsection{Citra}

Citra adalah suatu representasi (gambaran), kemiripan, atau imitasi dari suatu objek. Citra sebagai keluaran suatu sistem perekaman data dapat bersifat optik berupa foto, bersifat analog berupa sinyal-sinyal video seperti gambar pada monitor televisi, atau bersifat digital yang langsung disimpan pada suatu media penyimpanan[3].

\subsection{Pengolahan Citra Digital}

Pengolahan citra digital atau image processing merupakan suatu disiplin ilmu yang mempelajari hal-hal yang berkaitan dengan perbaikan kualitas gambar (peningkatan kontras, transformasi warna, restorasi citra), transformasi gambar (rotasi, translasi, transformasi geometric, skala), agar mudah diinterpretasi oleh manusi/mesin (komputer)[3]. Masukannya adalah citra dan keluarannya juga citra tapi dengan kualitas lebih baik dari pada citra masukan misal citra warnanya kurang tajam, 
kabur (blurring), dan mengandung noise (misal bintik-bintik putih) sehingga perlu ada pemrosesan untuk memperbaikan citra karena citra tersebut menjadi sulit diinterpretasikan karena informasi yang disampaikan menjadi berkurang.

\subsection{Deteksi Tepi (Edge Detection)}

Edge detection adalah proses untuk menemukan perubahan intensitas yang berbeda nyata dalam sebuah bidang citra. Deteksi tepi berfungsi untuk memperoleh tepi objek, deteksi tepi memamfaatkan perubahan nilai intensitas yang drastis pada batas dua area[3]. Tepi adalah himpunan pixel yang terhubung dan terletak pada batas dua area, tepi mengandung informasi yang sangat penting, informasi yang diperoleh dapat berupa bentuk maupun ukuran objek. Adapun beberapa contoh pendeteksi tepi yang pertama adalah operator berbasis Gradient (turunan pertama), yaitu operator robert, sobel, dan prewitt. Yang kedua adalah operator berbasis turunan kedua, yaitu operator Laplacian dan operator Laplacian Gaussian.

\subsection{Deteksi Tepi Sobel}

Sobel merupakan proses konvolusi dari jendela yang ditetapkan terhadap citra yang dideteksi. Agar perkiraan gradient berada tepat ditengah jendela, dalam konvolusi Sobel menggunakan jendela $3 \times 3$ [3].

$G x=\left[\begin{array}{lll}-1 & 0 & 1 \\ -2 & 0 & 2 \\ -3 & 0 & 1\end{array}\right] \quad G x=\left[\begin{array}{ccc}1 & 2 & 1 \\ 0 & 0 & 0 \\ -1 & -2 & -1\end{array}\right]$

Berdasarkan susunan piksel tetangga tersebut, besar gradient yang dihitung menggunakan operator sobel [2] adalah:

$|G|=\sqrt{ } \mathrm{G}^{2}{ }_{\mathrm{x}}+\mathrm{G}^{2} \mathrm{y}$

$|G|=|G x|+|G y|$

Adapun proses metode sobel ialah citra yang diinputkan akan dikonversi ke citra grayscale, kemudian dengan edge detection sobel untuk mendapatkan garis tepi. Hasil grayscale berupa citra warna keabu-abuan, sedangkan edge detection berupa citra hitam dan putih.

\subsection{Apel fuji}

Apel fuji (Malus Domestika) adalah salah satu dari beberapa jenis apel yang banyak memiliki zat antioksidan terutama dari kandungan buahnya. Apel fuji merupakan buah yang mempunyai antioksidan tertinggi yaitu 108mg catechin equivalents/100g apel. Selain buahnya kulit apel juga mengandung jenis serat pangan yang larut air dan mudah difermentasi yaitu pektin [3].

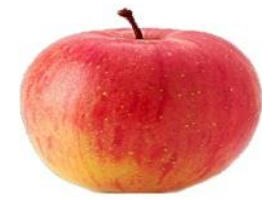

Gambar 1. Apel fuji

\section{HASIL DAN PEMBAHASAN}

Menghitung diameter apel fuji menggunakan deteksi tepi dapat mempermudah dalam melakukan proses perhitungan diameter. Deteksi tepi dari suatu citra mengandung informasi penting dari citra bersangkutan tepi citra dapat mempresentasikan objek-objek yang terkandung dalam citra tersebut, bentuk, dan ukurannya serta terkadang juga informasi tentang teksturnya, tepi citra merupakan posisi dimana intensitas piksel dari citra berubah dari nilai rendah ke nilai tinggi atau sebaliknya, proses deteksi tepi harus dapat menghasilkan deteksi dengan tepi yang jelas dan nyata. Metode sobel merupakan metode deteksi tepi citra dengan hasil tepi yang lebih jelas dan nyata. Jadi proses pengukuran diameter ini menggunakan perancangan aplikasi matlab dengan metode deteksi tepi sobel dan image processing.

Adapun langkah-langkah proses metode sobel :

1. citra yang diinputkan akan dikonversi ke citra grayscale, Hasil grayscale berupa citra warna keabu-abuan.

2. Mengambil nilai piksel citra grayscale.

3. Mengkonvolusi nilai piksel citra grayscale dengan kernel sobel horizontal dan vertikal.

Langkah pertama: Citra masukan dikonversi ke citra grayscale

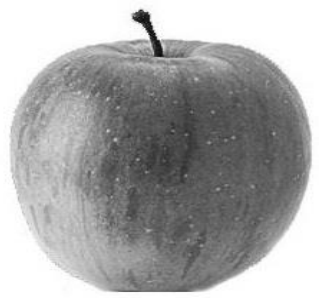




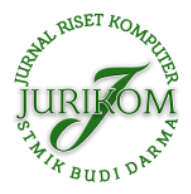

Gambar 2. citra grayscale

Langkah kedua untuk mengambil nilai-nilai pixel citra Grayscale dengan matlab yaitu.
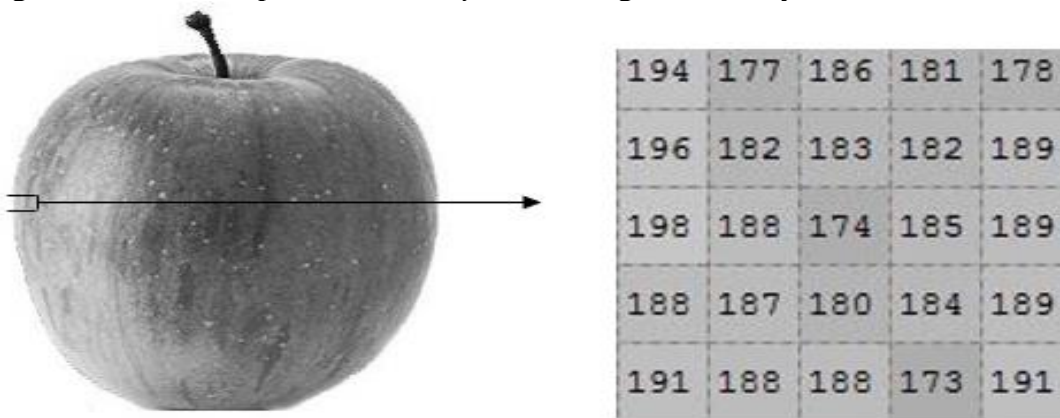

Gambar 3. Piksel Citra Graysclale.

Nilai-nilai piksel tersebut akan diproses dengan metode sobel untuk mendeteksi tepi pada citra tersebut. Nilai piksel dari citra di atas diproses sesuai dengan ketentuan dari metode sobel. Konvolusi citra grayscale dengan kernel Sobel horizontal(Gx) dan kernel Sobel vertikal(Gy)

\begin{tabular}{|c|c|c|c|c|}
\hline 194 & 177 & 186 & 181 & 178 \\
\hline 196 & 182 & 183 & 182 & 189 \\
\hline 198 & 188 & 174 & 185 & 189 \\
\hline 188 & 187 & 180 & 184 & 189 \\
\hline 191 & 188 & 188 & 173 & 191 \\
\hline
\end{tabular}

$$
G x=\left[\begin{array}{lll}
-1 & 0 & 1 \\
-2 & 0 & 2 \\
-3 & 0 & 1
\end{array}\right] \quad G x=\left[\begin{array}{ccc}
1 & 2 & 1 \\
0 & 0 & 0 \\
-1 & -2 & -1
\end{array}\right]
$$

Tempatkan kernel pada sudut kiri atas, kemudian hitung nilai pixel pada posisi $(1,1)$ dari kernel, berikut prosesnya.

\begin{tabular}{|l|l|l|l|l|}
\hline 194 & 177 & 186 & 181 & 178 \\
\hline 196 & 182 & 183 & 182 & 189 \\
\hline 188 & 188 & 174 & 185 & 189 \\
\hline 188 & 187 & 180 & 184 & 189 \\
\hline 191 & 188 & 188 & 173 & 191 \\
\hline
\end{tabular}

$\longrightarrow$\begin{tabular}{|l|l|l|l|l|}
\hline 0 & 0 & 0 & 0 & 0 \\
\hline 0 & 52 & & & 0 \\
\hline 0 & & & & 0 \\
\hline 0 & & & & 0 \\
\hline 0 & 0 & 0 & 0 & 0 \\
\hline
\end{tabular}

Hasil konvolusi $=52$ Nilai ini di hitung dengan cara berikut :

$|\mathrm{Gx}|=(-1 \times 194)+(-2 \times 196)+(-1 \times 188)+(0 \times 177)+(0 \times 182)+(0 \times 188)+(1 \times 186)+(2 \times 183)+(1 \times 174)=-48=48$

$\mathrm{Gy} \mid=(1 \times 194)+(0 \times 196)+(-1 \times 188)+(2 \times 177)+(0 \times 182)+(-2 \times 188)+(1 \times 186)+(0 \times 183)+(-1 \times 174)=-4=4$

$\mathrm{G}(1,1)=|G x|+|G y|=|48|+|4|=52$

Geser kernel satu pixel ke kanan, kemudian hitung nilai pixel pada posisi $(2,1)$ dari kernel.

\begin{tabular}{|l|l|l|l|l|}
\hline 194 & 177 & 186 & 181 & 178 \\
\hline 196 & 182 & 183 & 182 & 189 \\
\hline 188 & 188 & 174 & 185 & 189 \\
\hline 188 & 187 & 180 & 184 & 189 \\
\hline 191 & 188 & 188 & 173 & 191 \\
\hline
\end{tabular}$\longrightarrow \rightarrow$\begin{tabular}{|l|l|l|l|l|}
\hline 0 & 0 & 0 & 0 & 0 \\
\hline 0 & 52 & 10 & & 0 \\
\hline 0 & & & & 0 \\
\hline 0 & & & & 0 \\
\hline 0 & 0 & 0 & 0 & 0 \\
\hline
\end{tabular}

Hasil konvolusi $=10$ Nilai ini di hitung dengan cara berikut :

$|\mathrm{Gx}|=(-1 \mathrm{x} 177)+(-2 \times 182)+(-1 \times 188)+(0 \times 186)+(0 \times 183)+(0 \times 174)+(1 \times 181)+(2 \times 182)+(1 \times 185)=1$

$|\mathrm{Gy}|=(1 \times 177)+(0 \times 182)+(-1 \times 188)+(2 \times 186)+(0 \times 183)+(-2 \times 174)+(1 \times 181)+(0 \times 182)+(-1 \times 185)=9$

$\mathrm{G}(2,1)=|G x|+|G y|=|1|+|9|=10$

Geser kernel satu pixel ke kanan, kemudian hitung nilai pixel pada posisi $(3,1)$ dari kernel.

\begin{tabular}{|l|l|l|l|l|}
\hline 194 & 177 & 186 & 181 & 178 \\
\hline 196 & 182 & 183 & 182 & 189 \\
\hline 188 & 188 & 174 & 185 & 189 \\
\hline 188 & 187 & 180 & 184 & 189 \\
\hline 191 & 188 & 188 & 173 & 191 \\
\hline
\end{tabular}$\longrightarrow \longrightarrow$\begin{tabular}{|l|l|l|l|l|}
\hline 0 & 0 & 0 & 0 & 0 \\
\hline 0 & 52 & 10 & 52 & 0 \\
\hline 0 & & & & 0 \\
\hline 0 & & & & 0 \\
\hline 0 & 0 & 0 & 0 & 0 \\
\hline
\end{tabular}

Hasil konvolusi $=26$ Nilai ini di hitung dengan cara berikut :

$|\mathrm{Gx}|=(-1 \times 186)+(-2 \times 183)+(-1 \times 174)+(0 \times 181)+(0 \times 182)+(0 \times 185)(1 \times 178)+(2 \times 189)+(1 \times 189)=19$

$|\mathrm{Gy}|=(1 \times 186)+(0 \times 183)+(-1 \times 174)+(2 \times 181)+(0 \times 182)+(-2 \times 185)(1 \times 178)+(0 \times 189)+(-1 \times 189)=-7=7$

$\mathrm{G}(3,1)=|G x|+|G y|=|19|+|7|=26$ 
Geser kernel satu pixel ke kanan, kemudian hitung nilai pixel sampai pada posisi $(3,3)$ dari kernel.

\begin{tabular}{|l|l|l|l|l|}
\hline 194 & 177 & 186 & 181 & 178 \\
\hline 196 & 182 & 183 & 182 & 189 \\
\hline 188 & 188 & 174 & 185 & 189 \\
\hline 188 & 187 & 180 & 184 & 189 \\
\hline 191 & 188 & 188 & 173 & 191 \\
\hline
\end{tabular}$\longrightarrow \quad$\begin{tabular}{|l|l|l|l|l|}
\hline 0 & 0 & 0 & 0 & 0 \\
\hline 0 & 52 & 10 & 52 & 0 \\
\hline 0 & 50 & 10 & 46 & 0 \\
\hline 0 & 52 & 40 & 44 & 0 \\
\hline 0 & 0 & 0 & 0 & 0 \\
\hline
\end{tabular}

Hasil konvolusi $=44$ Nilai ini di hitung dengan cara berikut :

$|\mathrm{Gx}|(-1 \times 174)+(-2 \times 180)+(-1 \times 188)+(0 \times 185)+(0 \times 184)+(0 \times 173)+(1 \times 189)+(2 \times 189)+(1 \times 191)=36$

$|\mathrm{Gy}|(1 \times 174)+(0 \times 180)+(-1 \times 188)+(2 \times 185)+(0 \times 184)+(-2 \times 173)+(1 \times 189)+(0 \times 189)+(-1 \times 191)=8$

$\mathrm{G}(3,3)=|G x|+|G y|=|36|+|8|=44$

Dari hasil konvolusi gambar 3 didapatkan nilai perhitungan matrik 3x3 dengan matrik 5x5 dengan mengunakan operator Sobel dan hasil deteksi tepi, nilai yang diperoleh

\begin{tabular}{|c|c|c|c|c|}
\hline 0 & 0 & 0 & 0 & 0 \\
\hline 0 & 52 & 10 & 52 & 0 \\
\hline 0 & 50 & 10 & 46 & 0 \\
\hline 0 & 52 & 40 & 44 & 0 \\
\hline 0 & 0 & 0 & 0 & 0 \\
\hline
\end{tabular}

Adapun hasil deteksi tepi citra dari metode sobel dapat dilihat seperti gambar berikut :

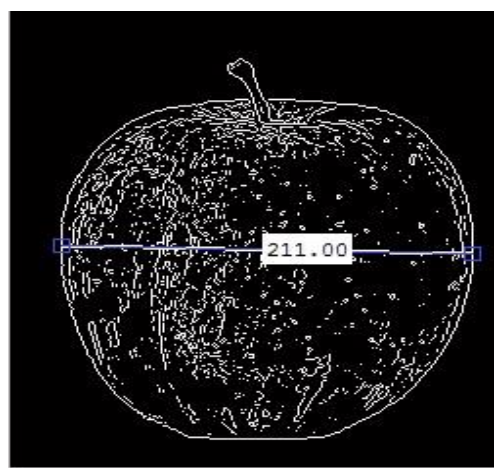

Gambar 4. Citra deteksi sobel

Hasil deteksi dengan metode sobel menunjukkan diameter apel fuji adalah 211.00 piksel, apabila nilai piksel tersebut dirubah ke $\mathrm{mm}$ maka hasil diameter apel fuji adalah 55,8 $\mathrm{mm}=5,58 \mathrm{~cm}$.

\subsection{Pengujian}

Adapun hasil dari tampilan program proses metode Sobel dan image processing untuk mendeteksi tepi pada citra pada image apel fuji dapat di lihat pada gambar di bawah ini : 


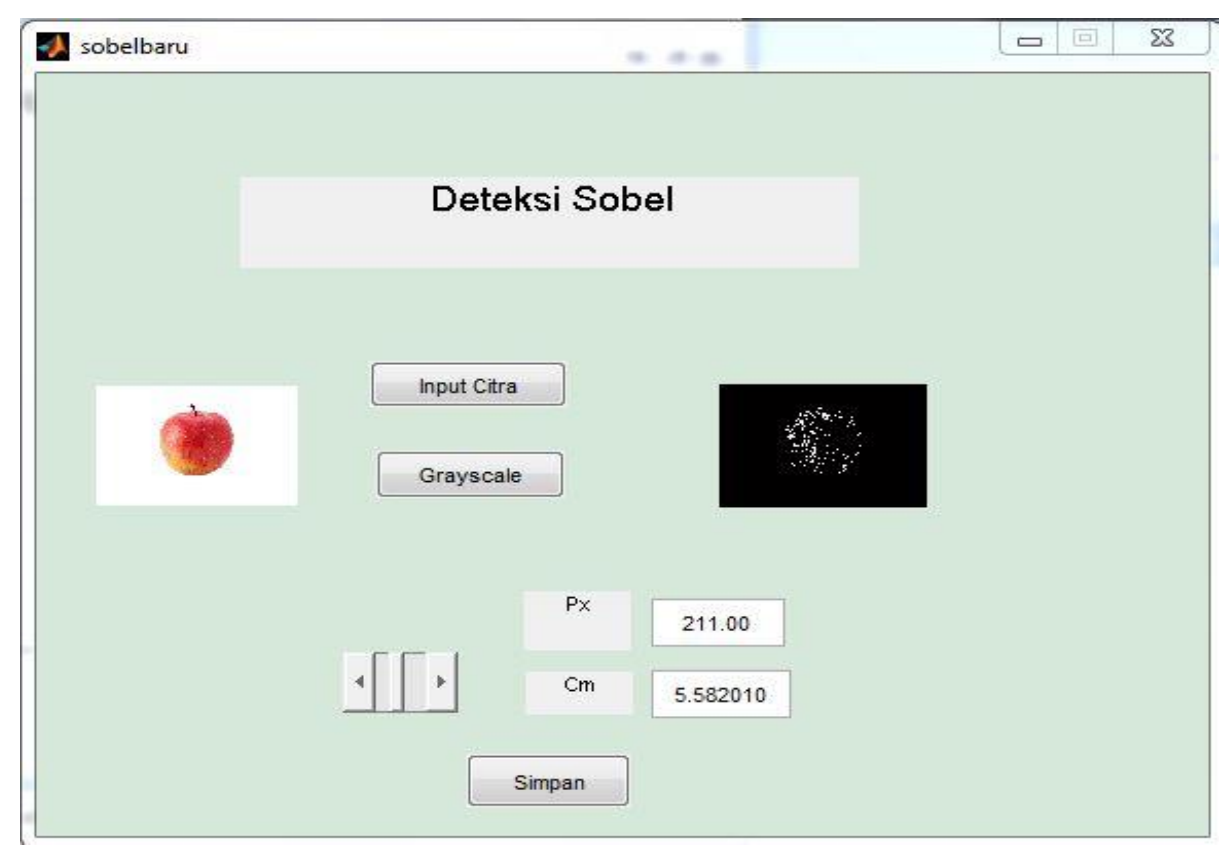

Gambar 5. Form Hasil Metode sobel

Pengujian aplikasi dilakukan untuk mengetahui apakah aplikasi sudah berjalan dengan baik dan benar. Pengujian terhadap aplikasi dilakukan dengan meng-input-kan citra.

Tabel 1. Hasil Pengujian

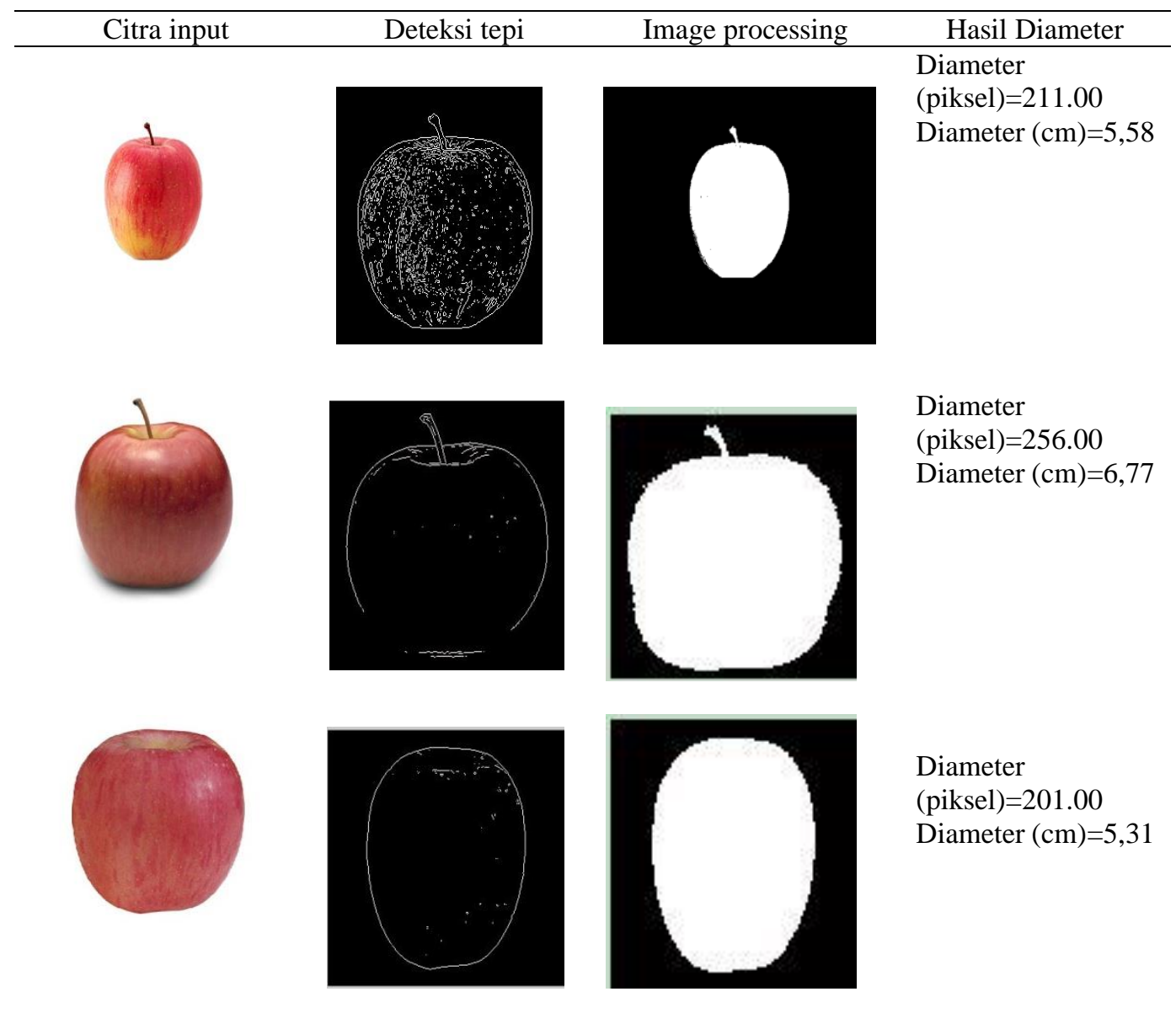

Berdasarkan hasil pengujian aplikasi deteksi tepi dengan menerapkan metode sobel edge detection dan image processing maka dapat dilihat perbedaan citra asli dengan citra hasil sobel dan image processing dan menghasilkan diameter apel fuji. 


\section{KESIMPULAN}

Adapun kesimpulan yang penulis peroleh berdasarkan hasil dari skripsi ini adalah sebagai berikut :

1. Sebuah citra digital terdiri dari pixel-pixel yang membentuk citra grayscale pada citra apel fuji tersebut.

2. Hasil deteksi tepi dari apel fuji, dapat digunakan untuk aplikasi pengolahan citra digital lain yang membutuhkan informasi mengenai komposisi pixel dari apel fuji.

3. Perancangan aplikasi dapat dibuat dengan menggunakan bahasa pemrograman Matlab dengan form hasil citra sobel dan image processing thresholding citra untuk mengetahui diameter apel fuji.

\section{REFERENCES}

[1] A. Soeb ,. S. Lukas dan S. N. Mian , "Implementasi Metode Laplacian of Gaussian Dalam Deteksi Tepi Citra Gigi Berlubang," dalam Seminar Nasional Teknologi Komputer \& Sains (SAINTEKS), Medan, 2020

[2] Agus Basukesti, Dwi Nugraheny Ade Noversi Putra, "Penerapan Metode Sobel Untuk Pengukuran Tinggi Badan Menggunakan Webcam," Compiler, vol. 2, no. 1, p. 6, Mei 2013.

[3] S.si.,M.kom T.Sutoyo, M.kom, Edy Mulyanto S.Si, Dr.Vincent Suhartono, Oky Dwi Nurhayati, and M.kom, M.T. Wijanarto, Teori Pengolahan Citra Digital , Benedicta Rini w, Ed. Yogyakarta: Andi, 2009.

[4] Darma Putra, Pengolahan Citra Digital, Westriningsih, Ed. Yogyakarta: Andi, 2010.

[5] http://darsatop.lecture.ub.ac.id/2014/06/apel-malus-domestica/

[6] Rosa A.S and M Shalahudin, Rekayasa Perangkat Lunak. Bandung: Informatika Bandung, 2015, vol. 3.

[7] Wahana Komputer, Ragam Aplikasi Pengolahan Image dengan Matlab. Jakarta: Komputindo, 2013.

[8] S. Surti , "Penerapan Metode Median Filter untuk Mereduksi Noise Speckle dan Salt\& Pepper pada Citra Ortokromatik," Building Informatics, Technology and Science (BITS), vol. 1, no. 1, pp. 34-41, 2019. 